\title{
Risk factors and clinical characteristics for bronchopulmonary dysplasia associated pulmonary hypertension in very-low-birth-weight infants
}

\author{
Junfang Sun ${ }^{1}$, Bowen Weng ${ }^{2}$, Xiaoyue Zhang ${ }^{2}$, Xiaoyun Chu $^{2}$ and Cheng Cai ${ }^{2^{*}}$
}

\begin{abstract}
Background: Pulmonary hypertension (PH) is a common complication of bronchopulmonary dysplasia (BPD) in very-low-birth-weight infants (VLBWIs). Although recent studies have increased awareness that PH contributes significantly to the high morbidity and mortality of BPD, the risk factors and clinical characteristics for PH in VLBWIs are little known.

Objectives: To investigate the risk factors and clinical characteristics for BPD-associated pulmonary hypertension (BPD-PH) in VLBWIs.

Methods: A retrospective case-control observational study of VLBWIs with BPD admitted to a neonatal intensive care unit (NICU) over 4 years. According to echocardiograms confirming elevated pulmonary artery pressure after 28 days after birth, we divided BPD infants into PH group $(n=18)$ and non-PH group $(n=65)$. We compared pre- and postnatal characteristics between VLBWIs with or without PH. Multivariable logistic regression analysis was conducted with backward selection.

Results: A total of 83 infants with BPD were divided into PH group $(n=18)$ or non-PH group $(n=65)$. The average birth weight of the infants with BPD was $1078.1 \mathrm{~g}$. Compared with those infants of the non-PH group, the birth weight of BPD-PH infants was significantly lower ( $968.1 \pm 187.7$ vs. $1108.5 \pm 185.8, P=0.006)$. Infants in the PH group had a higher incidence of patent ductus arteriosus (PDA) and underwent longer durations of oxygen therapy and mechanical ventilation compared to those in the non-PH group. In all subjects, birth weight $(\mathrm{OR} 0.995 ; 95 \% \mathrm{Cl}$ $0.991-0.999 ; P=0.025)$ and PDA (OR 13.355; 95\% Cl 2.950-60.469; $P=0.001)$ were found to be specific risk factors for BPD-PH in this cohort.
\end{abstract}

Conclusions: The study shows PDA and birth weight are specific risk factors for BPD-PH in VLBWIs.

Keywords: Risk factor, Bronchopulmonary dysplasia, Very-low-birth-weight infants, Pulmonary hypertension

*Correspondence: caicheng2004@163.com

2 Department of Neonatology, Shanghai Children's Hospital, Shanghai

Jiao Tong University, Shanghai 200062, China

Full list of author information is available at the end of the article

\section{Background}

Recently, owing to the use of prenatal steroids and postnatal surfactant (PS), improved ventilator strategies and advanced nursing techniques, the survival rate of premature infants especially VLBWIs and extremely low birth weight infants (ELBWIs) have increased [1]. In addition, BPD as a common chronic pulmonary 
complication of premature infants, has differed from its classical form described by Northway in 1967 [2-4]. Compared with the classical BPD, there are histologic differences in the "new" BPD, including simpler structure and reductions in the number of alveoli [5].

VLBW Is with BPD usually have a high risk of cardiovascular sequelae [6]. Among the cardiovascular sequelae, $\mathrm{PH}$ is associated with high morbidity and mortality in premature infants with BPD. Vascular remodeling, reduced alveolar-capillary surface area, abnormal vascular tone and reactivity lead to an increase in pulmonary vascular resistance (PVR) [7]. Increased PVR results in increased pulmonary arterial pressure.

At present, few studies on the clinical characteristics and outcomes of PH in VLBWIs with BPD have been published. Little is known about the risk factors for $\mathrm{PH}$ in VLBWIs with BPD, making it difficult to formulate screening strategies to identify $\mathrm{PH}$ in these infants. The aim of this study was to determine the clinical characteristics of PH associated with BPD in VLBWIs and investigate the risk factors for the disease.

\section{Material and methods Study design}

This was a retrospective study, conducted by reviewing medical records and data. The study protocol was approved by the institutional research ethics committee of Shanghai Children's Hospital (2015RY009-F01).

\section{Patients}

The retrospective review was performed of data from 109 infants with a gestational age of $<32$ weeks and a birth weight $<1500 \mathrm{~g}$ who were hospitalized between January 2016 and December 2019 in the NICU at Shanghai Children's Hospital. The exclusion criteria were congenital pulmonary malformation, diaphragmatic hernia, septic shock or incomplete case data $(n=26)$. None of the twenty-six excluded cases have undergone echocardiography screening at the above time. The case data was incomplete. Infants with a diagnosis of BPD [8] were divided into two groups, $\mathrm{PH}$ group and non-PH group, according to result of the echocardiogram screen conducted after at least 28 days after birth (over 36 weeks' corrected gestation or before discharged home). After recognition of $\mathrm{PH}, 2$ infants passed away in the $\mathrm{PH}$ group and 1 in the non- $\mathrm{PH}$ group ( $11 \%$ vs. $2 \%)$. Collect and retrospectively analyze data on the clinical characteristics of patients. The flow diagram showing the study design of the 83 premature infants with BPD and PH enrolled in this study is presented in Fig. 1.

\section{Definitions}

\section{Bronchopulmonary dysplasia}

We use the consensus definition of BPD for infants with $\mathrm{GA}<32$ weeks to classify our patient population [8]. Currently, the definition of BPD is based on respiratory support and supplemental oxygen therapy that a patient's need for at 36 weeks corrected gestational age (cGA). The diagnostic criteria for BPD in this study are based on the definition proposed in the conference of the National Institute of Child Health and Human Development (NICHD) in June 2000, infants suffer from BPD with supplemental oxygen required for a minimum of 28 days [8]. The definition, which categorizes the severity of BPD, is proposed (Table 1).

\section{Pulmonary hypertension}

In the present study, the diagnosis of $\mathrm{PH}$ depended entirely on echocardiography. The echocardiography was performed after at least 28 days after birth (over 36 weeks' corrected gestation or before discharge to home) for $\mathrm{PH}$ [9]. All echocardiographic examinations were conducted by a certain pediatric cardiologist team. The most objective measure of $\mathrm{PH}$ by echocardiogram is the estimated right ventricular systolic pressure (RVSP) derived from the tricuspid regurgitant jet velocity. The calculation of a systolic RV-to-right atrium pressure gradient by using the simplified Bernoulli equation (pressure gradient $=4 \times$ jet velocity ${ }^{2}$ ). The criteria for $\mathrm{PH}$ were met by any of the following findings [10, 11]: (1) RVSP greater than $40 \mathrm{mmHg}$; (2) RVSP/systemic systolic blood pressure greater than 0.5 ; (3) Cardiac shunt with bidirectional or right-to-left flow; (4) If no tricuspid regurgitation (TR) shunt presents then two out of following three criteria: (a) Any degree of interventricular septal flattening; (b) Right ventricular dilatation; (c) Right ventricular hypertrophy.

\section{Clinical variables}

The clinical characteristics were directly evaluated by a certain reviewer from medical records. Data extracted from the patient's medical records included birth history, maternal medical history, prenatal characteristics, postpartum medical history, and various complications. Prenatal diagnosis, such as gestational diabetes, gestational hypertension, preterm premature rupture of membranes (PPROM) is defined in accordance with the American College of Obstetrics and Gynecology (ACOG) guidelines [12-14]. Placental abruption is classically defined as the complete or partial separation of a normally implanted placenta before delivery [15]. Modified Bell's criteria were used to classify necrotizing enterocolitis (NEC) [16]. Hypoxemia was defined as arterial partial 
303 Patients identified $<32$ weeks $\&<1500$ grams

Jan. 2016-Dec. 2019

Hospitalized in NICU at Shanghai Children's Hospital

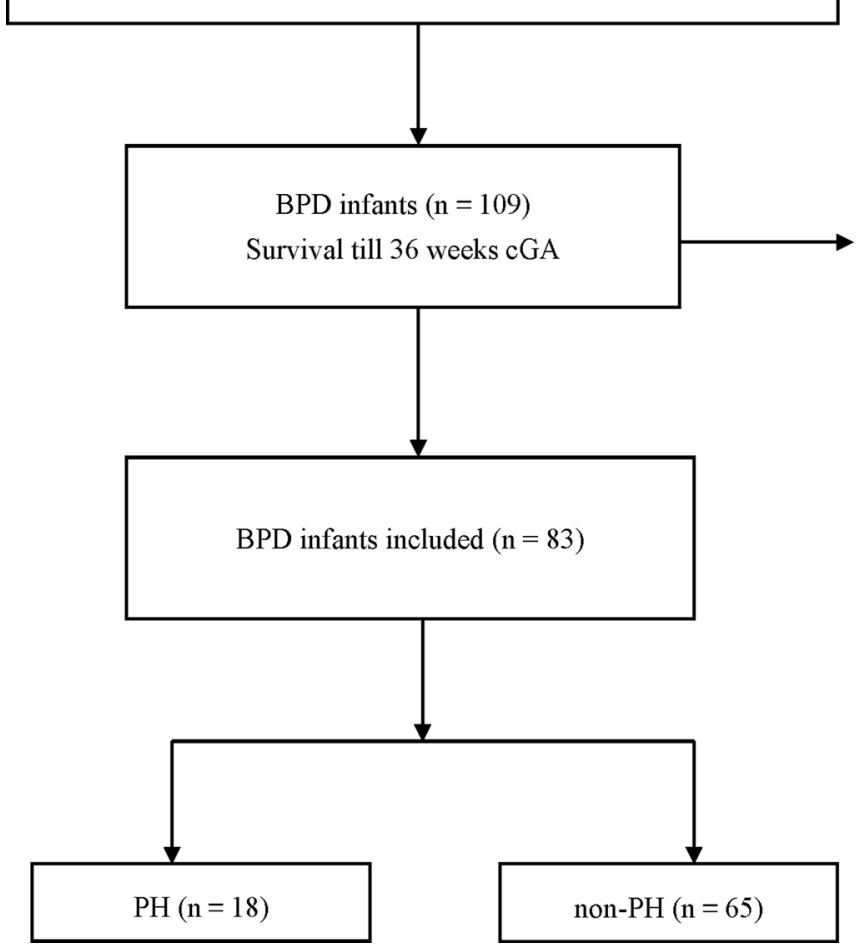

Excluded patients $(\mathrm{n}=26)$

Congenital pulmonary malformation

Diaphragmatic hernia

Septic shock

Incomplete case data

Fig. 1 Flow diagram showing the study design of BPD-PH infants enrolled in this study

Table 1 NICHD diagnostic criteria for severity of BPD

\begin{tabular}{ll}
\hline BPD severity & Criteria \\
\hline Mild & Supplemental oxygen required $\geq 28$ days, termination of supplemental oxygen by 36 weeks cGA or discharge \\
Moderate & Supplemental oxygen required $\geq 28$ days, requirement of $<30 \% \mathrm{O}_{2}$ at 36 weeks cGA or discharge \\
Severe & $\begin{array}{l}\text { Supplemental oxygen required } \geq 28 \text { days, requirement of } \geq 30 \% \mathrm{O}_{2} \text { and/or continuous positive airway pres- } \\
\text { sure or mechanical ventilation at } 36 \text { weeks cGA or discharge }\end{array}$
\end{tabular}

pressure of oxygen less than $60 \mathrm{~mm}$ of mercury. This value was extracted from the results of arterial blood gas analysis after the diagnosis of BPD and before the detection of $\mathrm{PH}$ by echocardiography.

\section{Statistical analysis}

All statistical analyses were performed using SPSS for Windows, version 27.0 Data were presented as mean $\pm S D$ or frequency. Chi-square test was used to analyze categorical variables. Independent sample t-test was used to compare normally distributed continuous variables. Risk factors for BPD-PH were analyzed with binary logistic regression model. The variables included in the multivariate analyses for $\mathrm{BPD}-\mathrm{PH}$ were gestational age, birth weight, PDA, duration of $\mathrm{O}_{2}$ therapy and duration of mechanical ventilation. A stepwise regression was utilized and in all analyses. $P<0.05$ was considered significant.

\section{Results}

\section{Patient selection}

As per Fig. 1, we found 109 preterm infants with BPD, whose birth weight (BW) was less than $1500 \mathrm{~g}$. According to the exclusion criteria, we had excluded 26 patients. The 
excluded cases included 2 severe BPD infants, 4 moderate BPD infants, and 20 mild BPD infants. A total of 83 infants with BPD were divided into PH group $(n=18)$ or non- $\mathrm{PH}$ group $(\mathrm{n}=65)$.

\section{Birth history}

Compared with those premature infants of the non-PH group, the birth weight of BPD-PH infants was significantly lower $(P=0.006)$. But there were no significant differences in sex, gestational age, small for gestational age (SGA) and Apgar score after five minutes $(P>0.05)$ (Table 2).

\section{Maternal medical history}

There were no significant differences between the patients of the two groups in terms of maternal age, cesarean section, gestational hypertension, gestational diabetes, placental abruption, and preterm premature rupture of membranes $(P>0.05)$ (Table 2$)$.

\section{Clinical characteristics}

Compared with infants in the non-PH group, the proportion of moderate to severe BPD infants in the $\mathrm{PH}$ group did not increase significantly $(P=0.130)$ (Table 2). Compared with infants without $\mathrm{PH}$, infants

Table 2 Baseline clinical characteristics of the study population

\begin{tabular}{|c|c|c|c|c|}
\hline Clinical characteristics & All study patients $(n=83)$ & Non-PH $(n=65)$ & $\mathrm{PH}(\mathrm{n}=18)$ & $P$ \\
\hline \multicolumn{5}{|l|}{ Birth history } \\
\hline Male & $46(55 \%)$ & $35(54 \%)$ & $11(61 \%)$ & 0.583 \\
\hline Birth weight, $g$ & $1078.1 \pm 194.0$ & $1108.5 \pm 185.8$ & $968.1 \pm 187.7$ & 0.006 \\
\hline Gestational age, weeks & $28.3 \pm 1.3$ & $28.4 \pm 1.2$ & $27.9 \pm 1.3$ & 0.132 \\
\hline \multicolumn{5}{|l|}{ 5-min Apgar scores } \\
\hline $0-3$ & $1(1 \%)$ & $0(0)$ & $1(6 \%)$ & \\
\hline $4-7$ & $15(18 \%)$ & $13(20 \%)$ & $2(11 \%)$ & 0.120 \\
\hline $8-10$ & $67(81 \%)$ & $52(80 \%)$ & 15(83\%) & \\
\hline Small for gestational age & $5(6 \%)$ & $2(3 \%)$ & $3(17 \%)$ & 0.066 \\
\hline \multicolumn{5}{|l|}{ Maternal medical history } \\
\hline Cesarean section & $41(49 \%)$ & $32(49 \%)$ & $9(50 \%)$ & 0.954 \\
\hline Maternal age, $\geq 35$ & $14(17 \%)$ & $9(14 \%)$ & $5(28 \%)$ & 0.162 \\
\hline Gestational diabetes & $7(8 \%)$ & $5(8 \%)$ & $2(11 \%)$ & 0.644 \\
\hline Gestational hypertension & $14(17 \%)$ & $11(17 \%)$ & $3(17 \%)$ & 0.979 \\
\hline PPROM & $18(22 \%)$ & $14(22 \%)$ & $4(22 \%)$ & 0.950 \\
\hline Placental abruption & $11(13 \%)$ & $9(14 \%)$ & $2(11 \%)$ & 0.762 \\
\hline \multicolumn{5}{|l|}{ Clinical characteristics } \\
\hline \multicolumn{5}{|l|}{ BPD severity } \\
\hline mild & $38(46 \%)$ & $32(49 \%)$ & $6(33 \%)$ & \\
\hline moderate & $27(32 \%)$ & $22(34 \%)$ & $5(28 \%)$ & 0.130 \\
\hline severe & $18(22 \%)$ & $11(17 \%)$ & $7(39 \%)$ & \\
\hline Pulmonary surfactant & $73(88 \%)$ & $56(86 \%)$ & $17(94 \%)$ & 0.339 \\
\hline Respiratory distress syndrome & $82(99 \%)$ & $64(98 \%)$ & 18(100\%) & 0.597 \\
\hline Duration of $\mathrm{O}_{2}$ therapy, days & $58.9 \pm 28.0$ & $55.5 \pm 27.8$ & $70.9 \pm 26.1$ & 0.038 \\
\hline Duration of mechanical ventilation, days & $51.4 \pm 27.5$ & $48.0 \pm 27.2$ & $63.9 \pm 25.4$ & 0.028 \\
\hline Duration of hospitalization, days & $75.0 \pm 24.5$ & $73.1 \pm 25.2$ & $81.9 \pm 20.8$ & 0.178 \\
\hline Hypoxemia & $81(98 \%)$ & $63(97 \%)$ & $18(100 \%)$ & 0.451 \\
\hline NEC, stage $\geq 2$ & $6(7 \%)$ & $5(8 \%)$ & $1(6 \%)$ & 1.000 \\
\hline Home oxygen & $3(4 \%)$ & $2(3 \%)$ & $1(6 \%)$ & 0.525 \\
\hline Death & $3(4 \%)$ & $1(2 \%)$ & $2(11 \%)$ & 0.117 \\
\hline \multicolumn{5}{|l|}{ Transthoracic echocardiography } \\
\hline Patent ductus arteriosus & $36(43 \%)$ & $21(32 \%)$ & 15(83\%) & 0.001 \\
\hline Atrial septal defect & $66(80 \%)$ & $51(78 \%)$ & $15(83 \%)$ & 0.650 \\
\hline Patent foramen ovale & $34(41 \%)$ & $29(45 \%)$ & $5(28 \%)$ & 0.199 \\
\hline Ventricular septal defect & $1(1 \%)$ & $1(2 \%)$ & $0(0)$ & 0.597 \\
\hline
\end{tabular}


with $\mathrm{PH}$ had a greater need for longer durations of oxygen therapy $(P=0.038)$ and mechanical ventilation (including invasive ventilation and non-invasive ventilation) $(P=0.028)$, as shown in Table 2 . The proportion of hypoxemia did not differ between infants with and without PH $(P=0.451)$ (Table 2). After recognition of $\mathrm{PH}, 2$ patients passed away in the $\mathrm{PH}$ group and 1 in the non-PH group ( $11 \%$ vs. $2 \%)$. There was no significant difference in mortality $(P=0.117)$ (Table 2).

\section{Transthoracic echocardiography}

Compared with those premature infants in the non-PH group, the incidence of PDA was significantly higher in the $\mathrm{PH}$ group $(P=0.001)$ (Table 2$)$. In the study, 4 patients underwent ligation of PDA, all of them in the $\mathrm{PH}$ group. Twenty-two patients were treated with NSAIDs to close the ductus, and 9 of them were in $\mathrm{PH}$ group. Compared with that of the non-PH group, there were no significant differences in other echocardiography results of the PH group $(P>0.05)$ (Table 2$)$.

\section{Logistic regression}

Univariate analysis for the comparison of clinical characteristics according to the presence or absence of $\mathrm{PH}$ in all subjects included in this study showed a statistically significant difference $(P<0.05)$ in five variables (Table 2): birth weight $(968.1 \pm 187.7$ vs. $1108.5 \pm 185.8$, $P=0.006)$, duration of oxygen therapy $(70.9 \pm 26.1 \mathrm{vs}$. $55.5 \pm 27.8, P=0.038)$, duration of mechanical ventilation $(63.9 \pm 25.4$ vs. $48.0 \pm 27.2, P=0.028)$, and PDA ( $83 \%$ vs. $32 \%, P=0.001)$. Based on the $P$ values on univariate analyses, a multivariate logistic regression model was performed to ascertain risk factors for development of BPD-PH. In all subjects, birth weight (OR 0.995; 95\% CI 0.991-0.999; $P=0.025$ ) and PDA (OR 13.355; 95\% CI 2.950-60.469; $P=0.001$ ) were found to be specific risk factors for BPD-PH in this cohort (Table 3).

Table 3 Risk factors for BPD-PH in VLBWls by binary logistic regression analysis

\begin{tabular}{llll}
\hline Clinical characteristics & OR & $\mathbf{9 5 \% C l}$ & $\boldsymbol{P}$ \\
\hline Birth weight, g & 0.995 & $0.991-0.999$ & 0.025 \\
Gestational age, weeks & 1.414 & $0.761-2.628$ & 0.273 \\
Duration of $\mathrm{O}_{2}$ therapy, days & 0.988 & $0.937-1.042$ & 0.663 \\
Duration of mechanical ventilation, days & 1.021 & $0.964-1.081$ & 0.472 \\
Patent ductus arteriosus & 13.355 & $2.950-60.469$ & 0.001 \\
\hline
\end{tabular}

\section{Discussion}

This retrospective study sought to determine the risk factors and clinical characteristics of infants with BPD$\mathrm{PH}$. In recent years, the incidence of $\mathrm{BPD}$ is on the rise because of the advances in NICU [17]. Prior studies have reported that the incidence of BPD-PH ranged from 8 to $36 \%$ [18]. This broad range may be explained by the heterogeneity of the studied populations, by varying management practices, or by the variability in the definition of $\mathrm{PH}$. In this study, the incidence of $\mathrm{PH}$ in premature infants with BPD was $21.7 \%(18 / 83)$. This incidence in the cohort was close to previous reports.

The causation is multifactorial in BPD-PH. We confirmed several well-known factors [19], and found the factors were also present in VLBW premature patients with BPD-PH. As previously shown, several factors associated with development of $\mathrm{PH}$ in BPD patients, including BW, small for gestational age, PDA, duration of oxygen therapy and duration of mechanical ventilation [20-23]. In the present study low birth weight was associated with the development of PH. However, we did not identify these SGA as risk factor for BPD-PH in the present study. The developmental stage of the lung tissue of infants with moderate to severe BPD was from the tubule stage to the vesicle stage. The pulmonary vascular abnormalities in BPD including impaired pulmonary angiogenesis, abnormal pulmonary vascular remodeling, heightened pulmonary vascular tone, and development of abnormal collateral circulations [4]. Several studies have shown that about $25 \%$ of premature infants with moderate to severe BPD would develop BPD-PH $[10,24]$. On the contrary, this study did not find that the severity of BPD was related to the development of PH. In the study, the duration of medical ventilation and oxygen therapy was significantly longer in the $\mathrm{PH}$ group than in the non- $\mathrm{PH}$ group. These findings are consistent with previous finding by Nagiub et al. [20]. It was also emphasized from the Arjaans and coworkers' study, that prolonged invasive mechanical ventilation would aggravate lung inflammation, causing pulmonary vascular remodeling, disrupting the normal lung development of premature infants [25]. Besides, the results of univariate analysis of this study found that the birth weight in $\mathrm{PH}$ group was significantly less than that in the non-PH group. A recent study by Collaco and coworkers described the risk factors for BPD-PH including low birth weight, low gestational age, and prolonged oxygen therapy [26]. Immature lung development is the root cause of BPD. Respiratory support is one of the important treatment measures for BPD. Prolonged oxygen therapy in PH group is expected. However, due to long-term exposure to the ventilator, the immature lung tissues will experience pulmonary inflammation, capillary endothelial cells damage 
and vascular remodeling, leading to increased pulmonary artery pressure. In this study, all patients with BPD received nebulized budesonide for addressing pulmonary inflammation. Therefore, we should adopt protective ventilation strategies to minimize the damage caused by mechanical ventilation [27]. Among 18 patients with $\mathrm{PH}$, only 1 was treated with sildenafil. There was no significant difference in mortality between the two groups $(P=0.117)$. A number of reasons could explain the lack of significant association with mortality, among them, the most likely one is probably the difference in our patient/ referral population.

Abnormal pulmonary circulation in patients with BPD, such as persistent ductus arteriosus, was related to the occurrence of $\mathrm{PH}$. The pulmonary blood flow increased due to ductal shunting. The increased blood flow through an immature pulmonary bed produces vascular remodeling that results in a postnatal increase in pulmonary vascular resistance [28]. In the present study, the incidence of PDA in the PH group was significantly higher than that in the non- $\mathrm{PH}$ group, which is consistent with previous reports. In addition, 4 patients underwent ligation of PDA, all of them in the PH group. Twenty-two patients were treated with NSAIDs to close the ductus, and 9 of them were in PH group. Bancalari and coworkers found that the persistence of PDA in BPD infants leads to continuous body-pulmonary shunt, which may be related to increased pulmonary artery pressure [28]. However, the PDA may also be the consequence of PH. Patients with PH may keep their ductus arteriosus patent to reduce right ventricular afterload, as a response mechanism. The interaction between PDA and PH needs further research.

\section{Conclusion}

In conclusion, we found that BW, PDA, duration of oxygen therapy and duration of mechanical ventilation were risk factors for BPD-PH. The survival rate of ones with $\mathrm{PH}$ was lower than that of infants who did not. Furthermore, the infants with $\mathrm{PH}$ had to undergo longer durations of oxygen therapy and mechanical ventilation than those without PH. PDA was a specific risk factor for $\mathrm{PH}$ in VLBWIs with BPD. Therefore, we suggest that a more active screening echocardiogram may be needed for diagnosing PH in VLBWIs with BPD. Further large cohort studies will be required to identify other risk factors for the development of PH in VLBWIs with BPD.

\section{Limitations}

This study has several limitations, including the lack of confirmation of $\mathrm{PH}$ by right heart catheterizations, which is the gold standard for diagnosis, because performing the invasive evaluations was not practical in this population. In addition, the study was a singlecenter retrospective clinical study and we lack the data on pre-natal steroid exposure. Besides, that measurements of these cardiac ultrasound results were not repeated from the raw images, but rather collected from individual clinical reports.

\section{Abbreviations \\ PH: Pulmonary hypertension; BPD: Bronchopulmonary dysplasia; VLBWIs: Very- low-birth-weight infants; BPD-PH: BPD-associated pulmonary hypertension; NICU: Neonatal intensive care unit; PDA: Patent ductus arteriosus; PS: Postnatal surfactant; ELBWIs: Extremely low birth weight infants; PVR: Pulmonary vascular resistance; CGA: Corrected gestational age; NICHD: National Institute of Child Health and Human Development; RVSP: Right ventricular systolic pressure; PPROM: Preterm premature rupture of membranes; ACOG: American College of Obstetrics and Gynecology; BW: Birth weight; NEC: Necrotizing enterocolitis; SGA: Small for gestational age.}

\section{Acknowledgements}

The authors would like to thank the patients for participating in this study. This study was supported by the National Natural Science Foundation of China (81571467). We would like to thank the team of the Department of Cardiac Ultrasound, Shanghai Children's Hospital for their assistance and advice.

\section{Authors' contributions}

SJF, CC: made substantial contributions to the conception and design, acquisition of data or analysis and interpretation of data. WBW, ZXY and CXY: were involved in drafting the manuscript or revising it critically for important intellectual content. CC: revised the manuscript and gave the final approval of the version to be published. The authors agree to be accountable for all aspects of the work in ensuring that questions related to the accuracy or integrity of any part of the work are appropriately investigated and resolved. All authors read and approved the final manuscript.

\section{Funding}

This work was supported by the National Natural Science Foundation of China (81571467)

Availability of data and materials

The datasets used and/or analyzed during the study is available from the corresponding author on reasonable request.

\section{Declarations}

\section{Ethics approval and consent to participate}

This is a retrospective study. There is no need to recruit subjects, and the informed consent of previous subjects cannot be obtained objectively. This study does not involve personal privacy. The Ethics Committee of Shanghai Children's Hospital has approved the waiver of informed consent. The study protocol was approved by Ethics Committee of Shanghai Children's Hospital (2015RY009-F01), all methods were carried out in accordance with relevant guidelines and regulations.

\section{Consent for publication \\ Not applicable.}

\section{Competing interests}

All authors certify that they have no affiliations with or involvement in any organization or entity with any financial interest, or non-financial interest in the subject matter or materials discussed in this manuscript. 


\section{Author details}

'Department of Respiratory Medicine, Shanghai Children's Hospital, Shanghai Jiao Tong University, Shanghai, China. ${ }^{2}$ Department of Neonatology, Shanghai Children's Hospital, Shanghai Jiao Tong University, Shanghai 200062, China.

Received: 7 June 2021 Accepted: 15 October 2021

Published online: 24 October 2021

\section{References}

1. lams JD, Romero R, Culhane JF, Goldenberg RL. Primary, secondary, and tertiary interventions to reduce the morbidity and mortality of preterm birth. Lancet. 2008:371(9607):164-75.

2. Northway WH Jr, Rosan RC, Porter DY. Pulmonary disease following respirator therapy of hyaline-membrane disease, Bronchopulmonary dysplasia. N Engl J Med. 1967;276(7):357-68.

3. Greenough A. Long-term pulmonary outcome in the preterm infant. Neonatology. 2008;93(4):324-7.

4. Alvira CM. Aberrant pulmonary vascular growth and remodeling in Bronchopulmonary dysplasia. Front Med (Lausanne). 2016;3:21.

5. Stenmark KR, Abman SH. Lung vascular development: implications for the pathogenesis of bronchopulmonary dysplasia. Annu Rev Physiol. 2005:67:623-61.

6. Abman SH. Monitoring cardiovascular function in infants with chronic lung disease of prematurity. Arch Dis Child Fetal Neonatal Ed. 2002;87(1):F15-8

7. De Paepe ME, Mao Q, Powell J, Rubin SE, DeKoninck P, Appel N, et al. Growth of pulmonary microvasculature in ventilated preterm infants. Am J Respir Crit Care Med. 2006;173(2):204-11

8. Jobe AH, Bancalari E. Bronchopulmonary dysplasia. Am J Respir Crit Care Med. 2001;163(7):1723-9.

9. Seo YH, Choi HJ. Clinical utility of echocardiography for early and late pulmonary hypertension in preterm infants: relation with Bronchopulmonary dysplasia. J Cardiovasc Ultrasound. 2017;25(4):124-30.

10. Mourani PM, Sontag MK, Younoszai A, Miller JI, Kinsella JP, Baker CD, et al. Early pulmonary vascular disease in preterm infants at risk for bronchopulmonary dysplasia. Am J Respir Crit Care Med. 2015;191(1):87-95.

11. Gowda S, Patil M. Factors associated with development of early and late pulmonary hypertension in preterm infants with bronchopulmonary dysplasia. Acta Paediatr. 2020;109(11):2420-1.

12. ACOG Practice Bulletin No. 190: Gestational Diabetes Mellitus. Obstet Gynecol. 2018;131(2):e49-64.

13. ACOG Committee on Practice Bulletins-Obstetrics. ACOG practice butletin. Diagnosis and management of preeclampsia and eclampsia. Obstet Gynecol. 2002;99(1):159-67.

14. ACOG Committee on Practice Bulletins-Obstetrics. ACOG Practice Bulletin No. 80: premature rupture of membranes. Clinical management guidelines for obstetrician-gynecologists. Obstet Gynecol. 2007;109(4):1007-19

15. Tikkanen M. Placental abruption: epidemiology, risk factors and consequences. Acta Obstet Gynecol Scand. 2011;90(2):140-9.

16. Neu J. Necrotizing enterocolitis: the search for a unifying pathogenic theory leading to prevention. Pediatr Clin N Am. 1996;43(2):409-32.

17. Stoll BJ, Hansen NI, Bell EF, Walsh MC, Carlo WA, Shankaran S, et al. Trends in care practices, morbidity, and mortality of extremely preterm neonates, 1993-2012. JAMA. 2015:314(10):1039-51.

18. Vayalthrikkovil S, Vorhies E, Stritzke A, Bashir RA, Mohammad K, Kamaluddeen $\mathrm{M}$, et al. Prospective study of pulmonary hypertension in preterm infants with bronchopulmonary dysplasia. Pediatr Pulmonol. 2019;54(2):171-8.

19. Nagiub M, Kanaan U, Simon D, Guglani L. Risk factors for development of pulmonary hypertension in infants with Bronchopulmonary dysplasia: systematic review and meta-analysis. Paediatr Respir Rev. 2017;23:27-32.

20. Bhat R, Salas AA, Foster C, Carlo WA, Ambalavanan N. Prospective analysis of pulmonary hypertension in extremely low birth weight infants. Pediatrics. 2012;129(3):e682-9.

21. An HS, Bae EJ, Kim GB, Kwon BS, Beak JS, Kim EK, et al. Pulmonary hypertension in preterm infants with bronchopulmonary dysplasia. Korean Circ J. 2010;40(3):131-6.

22. Ali Z, Schmidt P, Dodd J, Jeppesen DL. Predictors of bronchopulmonary dysplasia and pulmonary hypertension in newborn children. Dan Med J. 2013;60(8):A4688

23. Check J, Gotteiner N, Liu X, Su E, Porta N, Steinhorn R, et al. Fetal growth restriction and pulmonary hypertension in premature infants with bronchopulmonary dysplasia. J Perinatol. 2013;33(7):553-7.

24. Weismann CG, Asnes JD, Bazzy-Asaad A, Tolomeo C, Ehrenkranz RA, Bizzarro MJ. Pulmonary hypertension in preterm infants: results of a prospective screening program. J Perinatol. 2017;37(5):572-7.

25. Arjaans S, Wagner BD, Mourani PM, Mandell EW, Poindexter BB, Berger $\mathrm{RMF}$, et al. Early angiogenic proteins associated with high risk for bronchopulmonary dysplasia and pulmonary hypertension in preterm infants. Am J Physiol Lung Cell Mol Physiol. 2020;318(4):L644-54.

26. Collaco JM, Dadlani GH, Nies MK, Leshko J, Everett AD, McGrath-Morrow SA. Risk factors and clinical outcomes in preterm infants with pulmonary hypertension. PLoS ONE. 2016;11(10):0163904.

27. Jobe AH. The new bronchopulmonary dysplasia. Curr Opin Pediatr. 2011:23(2):167-72.

28. Bancalari E, Claure N, Gonzalez A. Patent ductus arteriosus and respiratory outcome in premature infants. Biol Neonate. 2005;88(3):192-201.

\section{Publisher's Note}

Springer Nature remains neutral with regard to jurisdictional claims in published maps and institutional affiliations.

Ready to submit your research? Choose BMC and benefit from:

- fast, convenient online submission

- thorough peer review by experienced researchers in your field

- rapid publication on acceptance

- support for research data, including large and complex data types

- gold Open Access which fosters wider collaboration and increased citations

- maximum visibility for your research: over 100M website views per year

At BMC, research is always in progress.

Learn more biomedcentral.com/submissions 